\title{
Effects of short-term particulate air pollution and nitrogen dioxide on blood pressure in older women: Longitudinal data from the Women's Health Initiative
}

\section{Tong Wen}

The Pennsylvania State University College of Medicine: Penn State College of Medicine

\section{Duanping Liao}

The Pennsylvania State University College of Medicine: Penn State College of Medicine

\section{Gregory A. Wellenius}

Boston University School of Public Health

\section{Eric A. Whitsel}

University of North Carolina at Chapel Hill Gillings School of Global Public Health

\section{Helene G. Margolis}

University of California Davis

\section{Leslie F. Tinker}

Fred Hutchinson Cancer Research Center

\section{James D. Stewart}

University of North Carolina at Chapel Hill Gillings School of Global Public Health

Jeff D. Yanosky ( $\sim$ JYanosky@phs.psu.edu )

Pennsylvania State University https://orcid.org/0000-0002-6196-655X

\section{Research}

Keywords: Air Pollution, Blood Pressure, Women's Health Initiative

Posted Date: October 18th, 2021

DOI: https://doi.org/10.21203/rs.3.rs-952531/v1

License: (c) (1) This work is licensed under a Creative Commons Attribution 4.0 International License. Read Full License 
1 Effects of short-term particulate air pollution and nitrogen dioxide on blood pressure in

2 older women: Longitudinal data from the Women's Health Initiative

3 Tong Wen ${ }^{1}$, Duanping Liao', Gregory A. Wellenius², Eric A. Whitsel ${ }^{3,4}$, Helene G. Margolis ${ }^{5}$,

4 Leslie F. Tinker ${ }^{6}$, James D. Stewart ${ }^{3}$, Jeff D. Yanosky ${ }^{1^{*}}$

5 Affiliations:

$6{ }^{1}$ Penn State College of Medicine, Department of Public Health Sciences, Division of

7 Epidemiology, Hershey, PA, USA

$8{ }^{2}$ Department of Environmental Health, Boston University School of Public Health, Boston, MA,

9 USA

$10{ }^{3}$ Department of Epidemiology, University of North Carolina Gillings School of Global Public

11 Health, Chapel Hill, NC, USA

$12{ }^{4}$ Department of Medicine, School of Medicine, University of North Carolina at Chapel Hill,

13 Chapel Hill, NC, USA

$14{ }^{5}$ Department of Internal Medicine, University of California, Davis, Davis, CA, USA

$15{ }^{6}$ Fred Hutchinson Cancer Research Center, Division of Public Health Sciences, Seattle,

16 Washington, USA

17 *Correspondence: jyanosky@phs.psu.edu

18 Abstract

19 Background: Short-term variations in particulate matter (PM) and traffic-related air pollutants

20 (e.g., nitrogen dioxide, $\mathrm{NO}_{2}$ ) have been associated with daily mortality and cardiovascular health

21 outcomes in previous studies. We aimed to evaluate whether short-term changes in PM in

22 three size fractions $\left(\mathrm{PM}_{2.5}, \mathrm{PM}_{2.5-10}\right.$, and $\left.\mathrm{PM}_{10}\right)$ and $\mathrm{NO}_{2}$ were associated with systolic and 
23 diastolic arterial blood pressure (SBP and DBP, respectively) in the Women's Health Initiative

24 Observational Study (OS) and Clinical Trials (CT).

25 Methods: We used linear mixed-effect models to estimate the association between short-term

26 air pollution concentrations and repeated measures of arterial blood pressure.

27 Results: We found statistically significant positive associations between short-term measures

28 (lag days 3-5) of $\mathrm{PM}_{2.5}$ as well as $\mathrm{NO}_{2}$ for both SBP and DBP in fully adjusted models when not

29 controlling for calendar time. Also, in only the $\mathrm{CT}, \mathrm{PM}_{10}$ and $\mathrm{PM}_{2.5-10}$ were associated with DBP

30 but not SBP. In fully adjusted models controlling for calendar time, associations with $\mathrm{PM}_{2.5-10}$

31 and $\mathrm{NO}_{2}$ remained statistically significant for DBP (except for $\mathrm{PM}_{2.5-10}$ in the OS). Specifically, in

32 the CT group, each IQR increase in lag 3-5 $\mathrm{NO}_{2}$ exposure $(9.88 \mathrm{ppb})$ was associated with a

$330.13 \mathrm{~mm} \mathrm{Hg}$ increase in DBP. Also, each IQR increase in lag 3-5 $\mathrm{PM}_{2.5-10}$ exposure (8.46 $\mu \mathrm{g} \mathrm{m}^{-}$

$\left.343^{3}\right)$ was associated with a $0.05 \mathrm{~mm} \mathrm{Hg}$ increase in DBP. Effect modification was found for body

35 mass index (BMI), socioeconomic position (SEP), diabetes, dietary sodium intake, combined

36 fruit and vegetable consumption, and long-term $\mathrm{PM}_{2.5}$ for $\mathrm{PM}_{2.5}, \mathrm{PM}_{10}$, and $\mathrm{NO}_{2}$. Shorter lag

37 periods (lag 0 through lag 2) typically exhibited lesser and, especially for SBP, sometimes

38 negative associations. In two-pollutant models of exposures lagged over 3-5 days, $\mathrm{NO}_{2}$

39 associations with DBP were stronger ( $0.20 \mathrm{~mm} \mathrm{Hg}$ per IQR), but those for $\mathrm{PM}_{2.5-10}$ were

40 attenuated to null, as compared to single-pollutant models.

41 Conclusions: Our findings are consistent with short-term (lag days 3-5) $\mathrm{PM}_{2.5-10}$ and $\mathrm{NO}_{2}$ levels

42 as risk factors for acute cardiovascular outcomes and cardiovascular disease, though two-

43 pollutant model results suggest $\mathrm{NO}_{2}$ is more likely responsible for the observed effects.

44 Keywords: Air Pollution, Blood Pressure, Women's Health Initiative

\section{Introduction}


46 Short-term variations (from days to weeks) in particulate matter (PM) and traffic-related air

47 pollutants such as nitrogen dioxide $\left(\mathrm{NO}_{2}\right)$ have been associated with daily mortality and

48 cardiovascular health outcomes in previous studies [1-3]. $\mathrm{PM}<2.5 \mu \mathrm{m}\left(\mathrm{PM}_{2.5}\right)$-mediated arterial

49 blood pressure (BP) elevation may potentially be an important part of the causal mechanism

50 leading to acute cardiovascular outcomes [4, 5]. One recent study from Women's Health

51 Initiative $(\mathrm{WHI})$ suggests that long-term exposure to $\mathrm{PM}_{2.5}$ and $\mathrm{PM}_{10}$ may be essential modifiable

52 risk factors for hypertension in post-menopausal women [6].

53 Findings from earlier studies of the effects of repeated short-term air pollutant exposures on BP

54 have been varied, though generally suggestive of positive associations [7-10]. One of these

55 studies conducted in California found that $\mathrm{PM}_{2.5}$ (specifically the $\mathrm{PM}_{2.5}$ component primary

56 organic carbon) was more strongly associated with BP measures than were gaseous pollutants

57 [7]. Additionally, traffic-related exposure measures have been identified as important modifiers

58 of the effect of $\mathrm{PM}_{2.5}$ on arterial BP in a diverse population from the MESA study [11]. One

59 randomized controlled trial in humans showed that short-term exposure to traffic-related air

60 pollution (i.e., diesel exhaust) was significantly associated with increased systolic BP (SBP) but

61 not diastolic BP (DBP) [12]. Findings from many epidemiological studies of short-term air

62 pollution effects on arterial BP have been analyzed using meta-analysis [13]; this meta-analysis

63 showed overall significant positive though not robust short-term associations between several

64 air pollutants $\left(\mathrm{PM}_{2.5}, \mathrm{PM}<10 \mu \mathrm{m}\left(\mathrm{PM}_{10}\right), \mathrm{NO}_{2}\right.$, and $\left.\mathrm{SO}_{2}\right)$ and increases in SBP and DBP, as well

65 as hypertension, an established risk factor for cardiovascular diseases. Blood pressure and air

66 pollutant levels (in many areas of the US) have both decreased over the past several decades

$67[14,15]$. Adar et al. found significant associations for both SBP and DBP with $\mathrm{PM}_{2.5}$ as well as

$68 \mathrm{NO}_{2}$ for exposure averaging periods of seven days and longer in adjusted models that did not

69 control for calendar time. However, when calendar time was included, those associations were

70 attenuated to null [16]. 
71 Few previous studies have evaluated short-term effects of PM (in multiple size fractions,

72 including $\mathrm{PM}_{2.5}$ (which originates from primary emissions from combustion sources and from

73 secondary formation in the atmosphere) and $2.5<\mathrm{PM}<10 \mu \mathrm{m}\left(\mathrm{PM}_{2.5-10}\right)$ (which is typically

74 generated from mechanical grinding or crushing, as well as from windblown dust)) and $\mathrm{NO}_{2}$ on

75 BP over the same short-term exposure period and those that have produced varied results [13].

76 Additionally, whether BMI, socioeconomic position (SEP), diabetes, combined fruit and

77 vegetable consumption, or long-term average $\mathrm{PM}_{2.5}$ levels may modify these effects is poorly

78 understood. In this study, we estimated the effects of short-term $\mathrm{PM}\left(\mathrm{PM}_{2.5}, 2.5<\mathrm{PM}<10 \mu \mathrm{m}\right.$

$79\left(\mathrm{PM}_{2.5-10}\right)$, and $\left.\mathrm{PM}_{10}\right)$ and $\mathrm{NO}_{2}$ on SBP and DBP using linear mixed effect models using data

80 from the Observational Study (OS) and Clinical Trials (CT) components of the Women's Health

81 Initiative (WHI) cohort. We evaluated effect modification by BMI, SEP, diabetes, dietary sodium

82 intake, combined fruit and vegetable consumption, and long-term average $\mathrm{PM}_{2.5}$ levels.

83 Additionally, we used two-pollutant models examine confounding effects by co-pollutant on BP.

\section{Methods}

85 Study population

86 The Woman's Health Initiative (WHI) is a nationwide prospective U.S. cohort across 40 clinical

87 centers in 24 states [17]. Post-menopausal women aged 50 to 79 years were recruited between

881993 and 1998, and followed through 2005. The WHI consists of two components, the

89 observational study component (OS: $n=93,696$ participants) and the clinical trials component

90 (CT: $n=68,132$ participants). We stratify our results by $\mathrm{WHI}$ cohort because of differences

91 between study designs, population attributes, missing-ness of data, and results in this study. In

92 the CT, repeated measurements were available from the screening visit and annual clinic visits

93 (Years 1-11); in the OS, repeated measurements were available from the screening visit and the

94 Year 3 visit. Our analysis was restricted to only those not currently taking anti-hypertensive

95 medication (OS: $n=69,490 ; C T: n=66,518)$ and therefore the final dataset contained 119,147 
96 (OS group) and 407,563 (CT group) observations. Because $\mathrm{PM}_{2.5}$ monitoring data were only

97 available after 1999 , and thus daily exposure models were unavailable prior to that date, about

$9866.8 \%$ of observations in the OS and $36.3 \%$ of observations in the CT were missing data on

$99 \quad \mathrm{PM}_{2.5}$ exposure over the study period.

100

Blood pressure measurements

101 Supine blood pressure was measured in the right arm after participants had been seated and at 102 rest for at least three minutes. SBP and DBP were computed by averaging two measurements; 103 if only one measurement was available, that single value was used.

104 Air pollution exposure assessment

105 Air pollution concentration estimates were available at geocoded residential locations of WHI 106 participants from a daily lognormal kriging model [18] (Liao et al. 2006) for $\mathrm{PM}_{2.5}, \mathrm{PM}_{10}$, and $107 \mathrm{NO}_{2} . \mathrm{PM}_{2.5-10}$ was estimated by subtracting model-predicted $\mathrm{PM}_{2.5}$ from model-predicted $\mathrm{PM}_{10}$. 108 This kriging model was validated using leave-one-out cross-validation and had a low average 109 prediction error of $0.06 \mu \mathrm{g} \mathrm{m}^{-3}$. Lagged exposure variables were calculated based on the index 110 date of the BP measurement and the period one-week prior, from zero (day of the 111 measurement; lag 0) to six days prior (lag 6) and were expressed as an interquartile range 112 (IQR) change in the pollutant to afford comparisons among air pollutants. Moving averages 113 were also calculated over corresponding lag periods (lag 0-1, lag 0-2, lag 0-3, etc.). Because

114 the effect estimates for individual lag periods were similar and largest (i.e., most positive) for lag 115 days 3,4 and 5 , summary measures of the exposures were calculated by averaging lagged 116 values from three to five days prior to the BP measurement (lag 3-5). Twelve-month moving117 average $\mathrm{PM}_{2.5}$ levels were estimated using spatio-temporal generalized additive mixed models 118 (GAMMs) at geocoded residential locations of WHI participants [19]. This GAMM model was 
119 validated using 10-set cross-validation and had high predictive accuracy with a cross-validation

$120 R^{2}$ of 0.77

\section{Covariates}

122 At baseline and during each annual follow-up visit, questionnaires were used to collect

123 demographic data. Covariates included in this analysis were age at visit, self-reported

124 race/ethnicity (White, Hispanic/Latino, Black/African-American, Asian/Pacific Islander, American

125 Indian/Alaskan Native and other), region (Northeast, South, Midwest, and West), day of the

126 week, season (spring, summer, fall, and winter), neighborhood SEP (continuous z-score (higher

127 z-score corresponds to higher SEP) calculated using six census tract-level variables [20] and

128 categorized by tertile), BMI ( $<25 \mathrm{~kg} / \mathrm{m}^{2} ; 25-30 \mathrm{~kg} / \mathrm{m}^{2} ;$ and $\left.>=30 \mathrm{~kg} / \mathrm{m}^{2}\right)$, dietary sodium intake

129 (mg/day and categorized by tertile), combined fruit and vegetable consumption (medium

130 servings/day and categorized by tertile), pack-years of smoking, diabetes, long-term average

$131 \mathrm{PM}_{2.5}$ concentrations (categorized by tertile), and calendar time expressed as the number of

132 years since baseline exam. For participants in the CT, treatment arm was also included as a

133 categorical variable.

\section{Statistical analysis}

135 Linear mixed-effects models:

136 We used linear mixed-effect (LME) models to estimate the association of air pollutant exposure

137 and arterial blood pressure. A compound symmetric variance matrix was specified in the models

138 to control for correlated errors between repeated measures. To estimate associations between

139 SBP and DBP measures and air pollutant exposure metrics, the following linear mixed-effects

140 regression model was fit to the data:

$$
y_{i j}=\beta_{0}+\sum_{p=1}^{P} \beta_{p} X_{p}+\alpha_{i}+b_{i} A g e_{i j}+e_{i j}
$$


142 where $y_{i j}$ represents either SBP or DBP measurements for subject $i$ and visit $j, \beta_{p}$ 's are fixed-

143 effect coefficients, $X_{p}$ 's are explanatory variables (including air pollutant concentrations,

144 confounders, and calendar time expressed as years since baseline exam). $\alpha_{i}$ is a subject-

145 specific random intercept included to account for the multiple observations available per subject,

146 and $b_{i}$ is a random slope for age. SAS v9.4 PROC MIXED was used for model fitting (except

147 upon non-convergence, when PROC GLIMMIX was used). A significance level of 0.05 was

148 used for all analyses.

149 Model selection:

150 First we evaluated unadjusted models between air pollutant concentrations $\left(\mathrm{PM}_{2.5}, \mathrm{PM}_{2.5-10}\right.$,

$151 \mathrm{PM}_{10}$, and $\mathrm{NO}_{2}$ ) and arterial blood pressure (SBP, DBP) in both OS and CT. For each pollutant,

152 the models included only a single lag period (lag days 0 to 6, in separate models) or a single

153 moving average. Next we evaluated the effect of lag 3-5 exposures in the models, then added

154 confounders, in sets, to form basic and adjusted models as described below. In basic models,

155 confounders included age, race/ethnicity, arm group (only for CT), census region, day of the

156 week, season, and a random slope for age. Next we added additional potential confounders to

157 the basic model; if the percent change in the air pollutant effect estimate was $>10 \%$, then the

158 variable was considered a confounder. If the percent change in the air pollutant effect estimate

159 was $<10 \%$, we then evaluated whether the Akaike information criterion (AIC) was lowered upon

160 inclusion of the variable and if so, the variable was considered a confounder. In adjusted

161 models, we further controlled for BMI, SEP, pack-years of smoking, and diabetes. Next, to

162 control for calendar time, we added the number of years since baseline exam to the fully

163 adjusted models. We evaluated fully-adjusted models with and without adjustment for calendar

164 time 1) to isolate the effect of controlling for calendar time and 2) to facilitate comparisons with

165 previous analyses which may or may not have controlled for calendar time. To evaluate effect 
modification, we fit fully adjusted models with interaction terms for the lag 3-5 air pollutant and each of BMI, SEP, diabetes, smoking, sodium intake, fruit and vegetable consumption, US Census Region (“Northeast”, “Midwest”, “South”, “West”), and long-term $\mathrm{PM}_{2.5}$ concentrations. When statistically significant effect modification was found ( $p$-value for interaction term $<0.05$ ),

170 stratified analyses were conducted. For pollutants which were found to have statistically

171 significant main effects in fully adjusted models controlling for calendar time, we further

172 examined these pollutants in two-pollutant models.

\section{Results}

174 During the study period (1993-2005), a total of 136,008 participants $(69,490$ in OS and 66,518 in

175 CT) were included in the analysis. Approximately 1 in 3 participants came from the western

176 region of the US and most of participants were white (>80\%). On average, participants were 177 overweight (i.e., BMI >= $25 \mathrm{~kg} \mathrm{~m}^{-2}$ ), with higher mean BMl among participants in CT than in the 178 OS, but this difference was not statistically significant. Characteristics of the study participants 179 and air pollutant concentrations are presented in Table 1.

180 Unadjusted models:

181 Regression coefficients (listed in the columns headed with " $\beta$ " in the tables) represent the 182 change in BP per unit change in air pollution concentration (after transformation of the air 183 pollutant concentration to the IQR scale). Results from unadjusted models using lag 3-5 184 exposures were varied and not consistent in direction. For SBP, unadjusted models using lag 185 3-5 exposures showed that short-term exposure to $\mathrm{PM}_{2.5-10}$ and $\mathrm{PM}_{10}$ were significantly 186 negatively associated in the OS and CT (except for $\mathrm{PM}_{2.5-10}$ in OS), while $\mathrm{NO}_{2}$ was significantly 187 positively associated in both the $\mathrm{OS}$ and CT. For DBP, $\mathrm{PM}_{2.5}, \mathrm{PM}_{2.5-10}, \mathrm{PM}_{10}$ and $\mathrm{NO}_{2}$ were 188 significantly positively associated in both the OS and CT (except for $\mathrm{PM}_{10}$ in the OS group and a 189 statistically significant negative association for $\mathrm{PM}_{2.5-10}$ in the OS group) (Table 2). 
191 Results from multivariable models with each potential confounder added showed that BMI, SEP, 192 pack-years of smoking, and diabetes were important confounders (in addition to those in the 193 basic models) among the three PM fractions as well as $\mathrm{NO}_{2}$ and for both SBP and DBP, 194 especially for $\mathrm{PM}_{2.5}$ and $\mathrm{NO}_{2}$ (Supplemental Material Table S1).

195 Results from basic and fully adjusted models without controlling for calendar time using single 196 lag days (0-6) are presented in Supplemental Material Tables S2A and Table S2B. Shorter 197 single lag periods (lag 0 through lag 2) showed significantly negative or null associations for PM $198\left(\mathrm{PM}_{2.5}, \mathrm{PM}_{2.5-10}\right.$ and $\left.\mathrm{PM}_{10}\right)$ with both SBP and DBP (except for $\mathrm{PM}_{2.5}$-DBP in OS group) as well 199 as $\mathrm{NO}_{2}$ with SBP. For longer lag periods, effects were consistent and largest (i.e., most 200 positive) for single lag periods 3,4 , and 5.

201 Fully adjusted models not controlling for calendar time and using lag 3-5 exposures included the 202 following confounders: age, race/ethnicity, treatment arm (only for the CT group), region, day of 203 the week, season, BMI, SEP, pack-years of smoking, and diabetes. In these fully adjusted 204 models not controlling for calendar time, $\mathrm{PM}_{2.5}$ and $\mathrm{NO}_{2}$ were significantly associated with both 205 SBP as well as DBP (regression coefficients from the LME models without effect modification 206 are presented in Table 2). Effect sizes for $\mathrm{NO}_{2}$ were largest among the pollutants considered 207 for SBP and DBP, except for $\mathrm{PM}_{2.5}$-SBP in the OS group. In the CT group, each IQR increase 208 in lag 3-5 $\mathrm{PM}_{2.5}$ exposure (an increment of $7.66 \mu \mathrm{g} \mathrm{m}^{-3}$ ) was associated with a $0.07 \mathrm{~mm} \mathrm{Hg}$ 209 increase in SBP and a $0.06 \mathrm{~mm} \mathrm{Hg}$ increase in DBP. By comparison, each IQR increase in lag $2103-5 \mathrm{NO}_{2}$ exposure (an increment of $9.88 \mathrm{ppb}$ ) was associated with a $0.45 \mathrm{~mm} \mathrm{Hg}$ increase in 211 SBP and a $0.38 \mathrm{~mm} \mathrm{Hg}$ increase in DBP. $\mathrm{PM}_{10}$ and $\mathrm{PM}_{2.5-10}$ were significantly associated with 212 DBP only in the CT group, again in fully adjusted models not controlling for calendar time. 
213 In fully adjusted models controlling for calendar time, the association between $\mathrm{NO}_{2}$ and DBP in

214 both the OS and CT groups remained statistically significant, as did the association between

$215 \mathrm{PM}_{2.5-10}$ and DBP in only the CT group. Specifically, in the CT group, each IQR increase in lag $2163-5 \mathrm{NO}_{2}$ exposure (9.88 ppb) was associated with a $0.13 \mathrm{~mm} \mathrm{Hg}$ increase in DBP (Table 2).

217 Also, each IQR increase in lag 3-5 $\mathrm{PM}_{2.5-10}$ exposure $\left(8.46 \mu \mathrm{g} \mathrm{m}^{-3}\right)$ was associated with a 0.05

$218 \mathrm{~mm} \mathrm{Hg}$ increase in DBP (Table 2). In the OS group, the effect size for lag 3-5 $\mathrm{NO}_{2}$ exposure

219 was larger and was $0.32 \mathrm{~mm} \mathrm{Hg}$.

220 Effect modification:

221 We evaluated effect modification in either 1) fully adjusted models not controlling for calendar

222 time or 2) in fully adjusted models controlling for calendar time, depending on whether main

223 effects were statistically significant in Table 2.

224 In fully adjusted models not controlling for calendar time, we found effect modification by BMI,

225 SEP, diabetes, and long-term $\mathrm{PM}_{2.5}$ levels for $\mathrm{PM}_{2.5}, \mathrm{PM}_{10}$, and $\mathrm{NO}_{2}$ ( $p$-value for interaction

226 terms $<0.05$; Table 3).

227 Because $\mathrm{PM}_{2.5-10}$-DBP and $\mathrm{NO}_{2}$-DBP associations were statistically significant in the fully 228 adjusted models controlling for calendar time, effect modification was evaluated in those 229 models. For NO2-DBP, we found effect modification by BMI, SEP, diabetes, dietary sodium 230 intake, and combined fruit and vegetable consumption (Table 4). No effect modification was 231 found between $\mathrm{PM}_{2.5-10}$ and DBP in the CT group.

\section{Effect modification by BMl:}

233 BMI modified the effects of lag 3-5 $\mathrm{PM}_{2.5}$ exposure as well as lag 3-5 $\mathrm{NO}_{2}$ exposure for SBP in 234 only the CT group, in models not controlling for calendar time. Also, BMI modified the effects of 235 lag 3-5 $\mathrm{NO}_{2}$ exposure for DBP in the CT group, again in models controlling for calendar time. 236 Stratified results showed both $\mathrm{PM}_{2.5}-\mathrm{SBP}$ associations and $\mathrm{NO}_{2}-\mathrm{SBP}$ associations were stronger 
237 and more positive among participants with higher $\mathrm{BMI}$; the $\mathrm{PM}_{2.5}$-SBP association was

238 statistically non-significant among those in the first (lowest) tertile of BMI (Table 3 \& Table 4).

\section{Effect modification by SEP:}

240 SEP also significantly modified the effect of lag 3-5 $\mathrm{PM}_{2.5}$ and $\mathrm{NO}_{2}$ in both the CT and OS for

241 both SBP and DBP, in models not controlling for calendar time (Table 3). For both $\mathrm{PM}_{2.5}$-SBP

242 and $\mathrm{PM}_{2.5}$-DBP, stratified associations were lower among those with higher SEP. For $\mathrm{NO}_{2}-\mathrm{SBP}_{\text {, }}$

243 stratified associations were again lower among those with higher SEP.

244 For $\mathrm{NO}_{2}$-DBP associations in models controlling for calendar time (Table 4), stratified

245 associations also were lower among those with higher SEP in both the OS and CT groups.

246 Effect modification by other factors:

247 For $\mathrm{PM}_{2.5}, \mathrm{PM}_{10}$, and $\mathrm{NO}_{2}$ lag 3-5 exposures, associations with SBP and DBP were stronger and

248 more positive among participants with diabetes compared to those without, in models not

249 controlling for calendar time (Table 3). Also, for lag 3-5 $\mathrm{PM}_{2.5}$ exposures, stratified associations

250 with DBP were stronger and more positive for the second and third tertiles of long-term $\mathrm{PM}_{2.5}$

251 level in the CT group.

252 For $\mathrm{NO}_{2}$-DBP associations in models controlling for calendar time, stratified associations were

253 lower among those with higher fruit and vegetable consumption in the OS group. Also, stratified

254 results by dietary sodium intake showed $\mathrm{NO}_{2}$-DBP associations were stronger and more

255 positive in the first and third tertile of sodium intake in the OS group, as compared to the second

256 tertile (Table 4).

257 Two-pollutant models controlling for calendar time:

258 In Table 2, only $\mathrm{PM}_{2.5-10}$ and $\mathrm{NO}_{2}$ had statistically significant main effects in fully adjusted models 259 controlling for calendar time and only for DBP, so only these two pollutants were used in two- 
260 pollutant models. Though $\mathrm{PM}_{2.5-10}$ and $\mathrm{NO}_{2}$ were significantly correlated in our analysis,

261 repeated measures correlation coefficients were low and ranged between 0.02 and 0.09 across

262 the seven lag periods lag 0 to lag 6.

263 Regression coefficients from single-pollutant and two-pollutant fully adjusted models controlling

264 for calendar time are presented in Table 5. For DBP, compared to single pollutant model

265 results, $\mathrm{NO}_{2}$ associations were stronger and more positive in two-pollutant models. However,

266 those for $\mathrm{PM}_{2.5-10}$ were attenuated to null. We also found effect modification by US Census

267 Region in the fully adjusted two-pollutant model controlling for calendar time (Supplemental

268 Material Table S3).

269 Discussion

270 Our findings indicate that short-term measures (lag days 3-5) of $\mathrm{PM}_{2.5}$ as well as $\mathrm{NO}_{2}$ are 271 consistently associated with changes in SBP and DBP in models not controlling for calendar

272 time. When evaluating $\mathrm{PM}_{2.5}$ and $\mathrm{NO}_{2}$ exposures averaged over lag days 3-5, patterns of

273 association were consistent and robust with respect to the direction of association.

274 However, results for shorter exposure periods (lag days 0-2) were attenuated, null, or

275 sometimes protective for PM in the three size fractions evaluated and for the $\mathrm{NO}_{2}-\mathrm{SBP}$

276 association. These findings are similar to results from other studies in different populations

277 showing protective or null short-term effects of $\mathrm{PM}[21-26]$ and $\mathrm{NO}_{2}[21,26]$ on blood pressure

278 on the same day or the previous 1-3 days. Specifically, statistically significant negative

279 associations were found between lag day 1, 2-, and $3 \mathrm{PM}_{10}$ and SBP as well as lag day $2 \mathrm{PM}_{10}$

280 and DBP, and between lag day 2 and $3 \mathrm{NO}_{2}$ and SBP. In contrast, statistically significant

281 positive associations were found between lag day 1 and lag day $2 \mathrm{NO}_{2}$ and DBP among

282 nonsmoking adults [21]. Statistically non-significant associations were also found between lag

283 day $1 \mathrm{PM}_{2.5}$ with both SBP and DBP among elders with no anti-hypertensive medication use 
284 [22]; similar results were found for $\mathrm{PM}_{2.5}$ exposures immediately and 24-h after a $2 \mathrm{hr}$ walk in 285 close proximity to traffic for both SBP an DBP among healthy adults [23]. In children, 286 statistically non-significant associations were found between lag day 0 (i.e., same day) 287 exposures to PM in three size fractions and SBP [24]; also statistically non-significant 288 associations were found between lag day 1 exposures to $\mathrm{PM}_{2.5}$ as well as $\mathrm{NO}_{2}$ and both SBP 289 and DBP in children [26]. Statistically significant negative associations were also found 290 between lag day 1-3 exposures to $\mathrm{PM}_{2.5}$ with SBP and DBP among young adults [25].

291 In our analysis, in models not controlling for calendar time, SEP, BMI, and diabetes were found 292 to be statistically significant effect modifiers. Two prior studies also reported effect modification 293 by $\mathrm{BMI}$ on the association between $\mathrm{PM}_{2.5}$ and $\mathrm{BP}[7,27]$. We also found effect modification by 294 long-term $\mathrm{PM}_{2.5}$ level on short-term exposure to $\mathrm{PM}_{2.5}$, a result consistent with earlier studies 295 which showed that the association between short-term $\mathrm{PM}_{2.5}$ and SBP was stronger in areas 296 with higher long-term $\mathrm{PM}_{2.5}$ levels $[27,28]$.

297 Our results for short-term (lag days 3-5) exposures, in models not controlling for calendar time, 298 were broadly consistent with those from previous studies. One panel study of 62 cardiac 299 rehabilitation patients showed a positive association between moving-average (over the 300 previous 5-days) $\mathrm{PM}_{2.5}$ exposure and SBP, as well as moving-averages of the previous 4-, and 301 5-day $\mathrm{PM}_{2.5}$ exposure levels and DBP [29]. Another panel study of 64 elderly subjects with 302 history of coronary heart diseases [7] found that multiday (3-day, 5-day, and 7-day) averaged air 303 pollution exposures were positively associated with increased SBP and DBP. In our single304 pollutant models, lag 3-5 $\mathrm{NO}_{2}$ had stronger effects on both SBP and DBP than did lag 3-5 $\mathrm{PM}_{2.5}$, 305 compared on an IQR basis. Stronger effects of $\mathrm{NO}_{2}$ on BP than those of $\mathrm{PM}_{2.5}$ have also been 306 shown in another study from Canada [30].

307 In models controlling for calendar time, our results are broadly consistent with those in Adar et 308 al. [16]. However in that analysis associations attenuated to null after controlling for calendar 
time (for exposure averaging periods of seven days, for example), whereas in the present study associations for lag 3-5 $\mathrm{PM}_{2.5-10}$ and $\mathrm{NO}_{2}$ remained statistically significant for DBP. Despite

311 remaining statistically significant, the effect sizes are small. However, they may still be clinically

312 relevant: Across the (somewhat skewed) distribution of exposure to $\mathrm{NO}_{2}$, comparing the most

313 highly-exposed individuals to the least, they may experience a change in exposure of

314 approximately three IQRs, and therefore the corresponding effect size would, using the larger

315 effect estimate from the OS, be $3^{*} 0.32=0.96 \mathrm{~mm} \mathrm{Hg}$ in DBP. In these models, we found effect

316 modification by SEP, BMI, and diabetes in the $\mathrm{NO}_{2}-\mathrm{DBP}$ association, suggesting that

317 participants with high BMI, low SEP, and diabetes may be particularly susceptible to the effects

318 of short-term $\mathrm{NO}_{2}$ on DBP. We also found that participants with more fruit and vegetable

319 consumption were less susceptible to the effects of $\mathrm{NO}_{2}$ on $\mathrm{DBP}$, suggesting potential dietary

320 intervention to mitigate air pollution-induced CVD risk [31]. We also noted effect modification by

321 dietary sodium intake, but the non-monotonic pattern in these associations does not support

322 meaningful causal interpretation.

323 Further, in two-pollutant models controlling for calendar time, associations of DBP with $\mathrm{NO}_{2}$ 324 became stronger than those in single-pollutant models, whereas $\mathrm{PM}_{2.5-10}$ associations were 325 attenuated to null. Zhao et al. [10] reported similar findings: In two-pollutant models including 326 both 1-day averaged $\mathrm{PM}_{2.5}$ and $\mathrm{NO}_{2}$, the statistically significant positive association between $327 \mathrm{PM}_{2.5}$ exposure and SBP attenuated to non-significant. We also note effect modification by US 328 Census Region consistent with results in Adar et al. [16], with the effects of lag 3-5 $\mathrm{NO}_{2}$ in the 329 two-pollutant model stronger in the South and West US Census Regions as compared to the 330 others.

331 However, some results from our analysis differ from earlier studies. Our study showed

332 statistically significant negative or null associations between individual lag day 0-2 air pollutant 333 exposures and both SBP and DBP. These negative associations persisted even when 
334 controlling for calendar time. In contrast, a panel study of 74 patients undergoing cardiac

335 rehabilitation [32] found a statistically significant positive association between 0-5 hour moving-

336 average $\mathrm{PM}_{2.5}$ exposure and SBP, with each IQR increase corresponding to an increase of 0.94

$337 \mathrm{~mm} \mathrm{Hg}(95 \% \mathrm{Cl}: 0.02-1.87)$. They also found statistically non-significant associations between

$338 \mathrm{PM}_{2.5}$ in individual lag periods (evaluating lag days $0,1,2,3$, and 4 separately) and DBP, which

339 is inconsistent with our findings. In another study, Dvonch et al. [28] reported that short-term

340 exposure (i.e., lag day 2) to $\mathrm{PM}_{2.5}$ was positively associated with SBP among all subjects,

341 suggesting a positive effect more acute than in our findings. These differences could be due to

342 differences in study population or to different exposure estimation procedures. A recent meta-

343 analysis of air pollution exposure and blood pressure reported substantial heterogeneity in effect

344 estimates on blood pressure for $\mathrm{PM}_{2.5}, \mathrm{PM}_{10}$, and $\mathrm{NO}_{2}$; also, $\mathrm{NO}_{2}$ had a larger meta-estimated

345 association with DBP than $\mathrm{PM}_{2.5}$ [13]. Their analysis also provided evidence of publication bias

346 for the association between $\mathrm{NO}_{2}$ and DBP. Also, earlier studies have documented evidence of

347 spatial and temporal variability of particulate pollution with regard to sources and chemical

348 composition [33, 34], and as such differences in PM composition, as discussed in Giorgini et al.

349 [5], could be another reason our findings differ from those in earlier studies.

350 This study has several strengths. One is the large sample size and recruitment from many

351 areas of the US which allowed us to perform stratified analysis with sufficient statistical power;

352 also the longitudinal study design using repeated measurements of blood pressure increased

353 statistical power to detect associations between air pollution exposures and BP measures.

354 Secondly, the estimates of air pollution exposure from daily lognormal kriging models contain

355 greater temporal (i.e., daily) and spatial (including urban-scale gradients) resolution than in

356 previous studies using conventional exposure assessment methods. Our study also has

357 several limitations. The first concerns the lack of $\mathrm{PM}_{2.5}$ monitoring before 1999. Second, we

358 were unable to control for other potential confounders such as physical activity and occupational 
exposure. The third is exposure error; a small amount of spatial error is unavoidable when performing spatial interpolation and kriging models did not include very local, micro- to neighborhood-scale information (or their proxies) on air pollutant levels. Of course, where

362 monitoring was sparse, interpolation was based on distant measurements. The fourth is limited 363 generalizability. The findings from this study may not be generalizable to males, nor to younger, 364 pre-menopausal women in the U.S.

365 In conclusion, our findings are consistent with short-term (lag days 3-5) $\mathrm{PM}_{2.5-10}$ and $\mathrm{NO}_{2}$ levels

366 as risk factors for acute cardiovascular outcomes and cardiovascular disease, though two-

367 pollutant model results suggest $\mathrm{NO}_{2}$ is more likely responsible for the observed effects among 368 elderly women not taking anti-hypertensive medication.

\section{Supplementary information}

370 Additional file 1: Table S1. Effects of an IQR change in air pollutant concentration on systolic 371 blood pressure (SBP) and diastolic blood pressure (DBP) in basic models with varying levels of 372 adjustment in the WHI Observational Study (OS) and Clinical Trials (CT) components. Table

373 S2A. Associations between an IQR change in air pollutant concentration and systolic blood 374 pressure (SBP) and diastolic blood pressure (DBP) for single lag days (0-6) based on basic 375 models. Table S2B. Associations between an IQR change in air pollutant concentration and 376 systolic blood pressure (SBP) and diastolic blood pressure (DBP) for single lag days (0-6) 377 based on fully adjusted models. Table S3. Single- and two-pollutant models of lag 3-5 day air 378 pollutant exposures based on fully adjusted models + calendar time stratified by US Census 379 Region.

\section{Abbreviations}

381 PM: Particulate matter; $\mathrm{PM}_{2.5}$ : Particulate matter $<2.5 \mu \mathrm{m} ; \mathrm{PM}_{2.5-10}$ : Particulate matter $>2.5 \mu \mathrm{m}$ 382 and <10 $\mu \mathrm{m} ; \mathrm{PM}_{10}$ : Particulate matter <10 $\mu \mathrm{m} ; \mathrm{NO}_{2}$ : nitrogen dioxide; BP: Blood pressure; SBP: 
383 Systolic blood pressure; DBP: diastolic blood pressure; WHI: Women's Health Initiative; OS:

384 Observational Study; CT: Clinical Trials; BMI: Body mass index; SEP: Socioeconomic position;

385 IQR: Interquartile range; GAMM: Generalized additive mixed models; LME: Linear mixed effect 386 models.

\section{$387 \quad$ Funding}

388 This study was supported by National Institutes of Health grant \#1 R01 ES020871-01A1.

\section{Acknowledgements}

390 The authors would like to thank the contribution from all WHI investigators and participants.

\section{Authors' contributions}

392 Gregory A. Wellenius, Eric A. Whitsel, Duanping Liao, Jeff D. Yanosky, Leslie F. Tinker, and 393 James D. Stewart helped secure funding for the project. Jeff D. Yanosky and Tong Wen 394 conducted data analysis and manuscript writing. Eric A. Whitsel and James D. Stewart 395 contributed to data collection and data cleaning. Eric A. Whitsel, Helene G. Margolis, Duanping 396 Liao, Leslie F. Tinker, and Gregory A. Wellenius provided suggestions to the data analysis, 397 reviewed, and revised the manuscript. The authors read and approved the final manuscript.

\section{Availability of data and materials}

399 Supporting data is not available.

400 Ethics approval and consent to participate

401 Informed consent was provided from all study participants.

\section{Consent for publication}

403 The authors consent to publication.

\section{Competing interests}


405 The authors, with the exception of Gregory A. Wellenius, declare that they have no competing 406 interests. Dr. Wellenius serves as a paid consultant for the Health Effects Institute (Boston, MA) 407 and Google, LLC (Mountain View, CA).

\section{Authors' information}

409 Tong Wen, Penn State College of Medicine, Department of Public Health Sciences, Division of 410 Epidemiology, Hershey, PA, USA, twen@phs.psu.edu; Duanping Liao, Penn State College of 411 Medicine, Department of Public Health Sciences, Division of Epidemiology, Hershey, PA, USA, 412 dliao@phs.psu.edu; Gregory A. Wellenius, Department of Environmental Health, Boston 413 University School of Public Health, Boston, MA, USA, wellenius@bu.edu; Eric A. Whitsel, 414 Department of Epidemiology, University of North Carolina Gillings School of Global Public 415 Health, Chapel Hill, NC, USA, Department of Medicine, School of Medicine, University of North 416 Carolina at Chapel Hill, Chapel Hill, NC, USA, eric whitsel@med.unc.edu; Helene G. Margolis, 417 Department of Internal Medicine, University of California, Davis, Davis, CA, USA,

418 hgmargolis@ucdavis.edu; Leslie F. Tinker, Fred Hutchinson Cancer Research Center, Division 419 of Public Health Sciences, Seattle, Washington, USA, Itinker@WHI.org; James D. Stewart, 420 Department of Epidemiology, University of North Carolina Gillings School of Global Public 421 Health, Chapel Hill, NC, USA, j.stewart@unc.edu; Jeff D. Yanosky, Penn State College of 422 Medicine, Department of Public Health Sciences, Division of Epidemiology, Hershey, PA, USA, 423 jyanosky@phs.psu.edu.

\section{References:}

425 1. Orellano P, Reynoso J, Quaranta N, Bardach A, Ciapponi A. Short-term exposure to 426 particulate matter $\left(\mathrm{PM}_{10}\right.$ and $\left.\mathrm{PM}_{2.5}\right)$, nitrogen dioxide $\left(\mathrm{NO}_{2}\right)$, and ozone $\left(\mathrm{O}_{3}\right)$ and all-cause 427 and cause-specific mortality: Systematic review and meta-analysis. Environ Int.

$428 \quad$ 2020;142:105876. doi:10.1016/j.envint.2020.105876 
2. Mills IC, Atkinson RW, Kang S, Walton H, Anderson HR. Quantitative systematic review of

430 the associations between short-term exposure to nitrogen dioxide and mortality and hospital 431 admissions. BMJ Open. 2015;5(5):e006946. Published 2015 May 11. doi:10.1136/bmjopen432 2014-006946.

433 3. Wu CF, Shen FH, Li YR, et al. Association of short-term exposure to fine particulate matter 434 and nitrogen dioxide with acute cardiovascular effects. Sci Total Environ. 2016;569-570:300305. doi:10.1016/j.scitotenv.2016.06.084.

4. Brook RD, Rajagopalan S. Particulate matter, air pollution, and blood pressure. Journal of 437 the American Society of Hypertension 2009; 3(5):332-350.

438 5. Giorgini P, Di Giosia P, Grassi D, Rubenfire M, Brook RD, Ferri C. Air Pollution Exposure 439 and Blood Pressure: An Updated Review of the Literature. Curr Pharm Des. 2016;22(1):28-

$440 \quad$ 51. doi:10.2174/1381612822666151109111712

441 6. Honda T, Eliot MN, Eaton CB, et al. Long-term exposure to residential ambient fine and 442 coarse particulate matter and incident hypertension in post-menopausal women. Environ Int. $443 \quad$ 2017;105:79-85. doi:10.1016/j.envint.2017.05.009

444 7. Delfino RJ, Tjoa T, Gillen DL, Staimer N, Polidori A, Arhami M, et al. Traffic-related air 445 pollution and blood pressure in elderly subjects with coronary artery disease. Epidemiology. $446 \quad$ 2010;21(3):396-404.

447 8. Hampel R, Lepeule J, Schneider A, et al. Short-term impact of ambient air pollution and air 448 temperature on blood pressure among pregnant women. Epidemiology. 2011;22(5):671449 679. doi:10.1097/EDE.0b013e318226e8d6

450 9. Hoffmann B, Luttmann-Gibson H, Cohen A, et al. Opposing effects of particle pollution, 451 ozone, and ambient temperature on arterial blood pressure. Environ Health Perspect. 452 2012;120(2):241-246. doi:10.1289/ehp.1103647 
10. Zhao A, Chen R, Wang C, et al. Associations between size-fractionated particulate air

454 pollution and blood pressure in a panel of type II diabetes mellitus patients. Environ Int.

$455 \quad$ 2015;80:19-25. doi:10.1016/j.envint.2015.03.003

456 11. Auchincloss AH, Diez Roux AV, Dvonch JT, Brown PL Barr RG, Daviglus ML, Goff Jr. DC,

457 Kaufman JD, O'Neill MS. Associations between recent exposure to ambient fine particulate

458 matter and blood pressure in the Multi-Ethnic Study of Atherosclerosis (MESA).

$459 \quad$ Environmental Health Perspectives 2008; 116(4):486-491.

460 12. Cosselman KE, Krishnan RM, Oron AP, et al. Blood pressure response to controlled diesel

461 exhaust exposure in human subjects. Hypertension. 2012;59(5):943-948.

462 doi:10.1161/HYPERTENSIONAHA.111.186593

463 13. Yang BY, Qian Z, Howard SW, et al. Global association between ambient air pollution and

464 blood pressure: A systematic review and meta-analysis. Environ Pollut. 2018;235:576-588.

465 doi:10.1016/j.envpol.2018.01.001

466 14. Brauer M, Freedman G, Frostad J, et al. Ambient Air Pollution Exposure Estimation for the

467 Global Burden of Disease 2013. Environ Sci Technol. 2016;50(1):79-88.

468 doi:10.1021/acs.est.5b03709

469 15. NCD Risk Factor Collaboration (NCD-RisC). Worldwide trends in blood pressure from 1975

470 to 2015: a pooled analysis of 1479 population-based measurement studies with $19 \cdot 1$ million

471 participants [published correction appears in Lancet. 2020 Sep 26;396(10255):886]. Lancet.

$472 \quad$ 2017;389(10064):37-55. doi:10.1016/S0140-6736(16)31919-5

473 16. Adar SD, Chen YH, D'Souza JC, et al. Longitudinal Analysis of Long-Term Air Pollution

474 Levels and Blood Pressure: A Cautionary Tale from the Multi-Ethnic Study of

475 Atherosclerosis. Environ Health Perspect. 2018;126(10):107003. doi:10.1289/EHP2966

476 17. Design of the Women's Health Initiative clinical trial and observational study. The Women's

477 Health Initiative Study Group. Control Clin Trials. 1998;19(1):61-109. 
478 18. Liao D, Peuquet DJ, Duan Y, et al. GIS approaches for the estimation of residential-level 479 ambient PM concentrations. Environ Health Perspect. 2006;114(9):1374-1380.

$480 \quad$ doi:10.1289/ehp.9169

481 19. Yanosky, J.D., Paciorek, C.J., Laden, F. et al. Spatio-temporal modeling of particulate air 482 pollution in the conterminous United States using geographic and meteorological predictors.

483 Environ Health 13, 63 (2014). https://doi.org/10.1186/1476-069X-13-63

484 20. Diez Roux AV, Merkin SS, Arnett D, Chambless L, Massing M, Nieto FJ, Sorlie P, Szklo M, 485 Tyroler HA, Watson RL. Neighborhood of residence and incidence of coronary heart 486 disease. N Engl J Med 2001;345(2):99-106.

487 21. Chen SY, Su TC, Lin YL, Chan CC. Short-term effects of air pollution on pulse pressure 488 among nonsmoking adults. Epidemiology. 2012;23(2):341-348.

489 doi:10.1097/EDE.0b013e3182452f1d

490 22. Jacobs L, Buczynska A, Walgraeve C, et al. Acute changes in pulse pressure in relation to 491 constituents of particulate air pollution in elderly persons. Environ Res. 2012;117:60-67. 492 doi:10.1016/j.envres.2012.05.003

493 23. Mirowsky JE, Peltier RE, Lippmann M, et al. Repeated measures of inflammation, blood 494 pressure, and heart rate variability associated with traffic exposures in healthy adults. 495 Environ Health. 2015;14:66. Published 2015 Aug 15. doi:10.1186/s12940-015-0049-0 496 24. Pieters N, Koppen G, Van Poppel M, et al. Blood Pressure and Same-Day Exposure to Air 497 Pollution at School: Associations with Nano-Sized to Coarse PM in Children. Environ Health 498 Perspect. 2015;123(7):737-742. doi:10.1289/ehp.1408121

499 25. Ren M, Zhang H, Benmarhnia T, et al. Short-term effects of real-time personal PM2.5 500 exposure on ambulatory blood pressure: A panel study in young adults. Sci Total Environ. $501 \quad$ 2019;697:134079. doi:10.1016/j.scitotenv.2019.134079 
26. Mann JK, Lutzker L, Holm SM, et al. Traffic-related air pollution is associated with glucose

503 dysregulation, blood pressure, and oxidative stress in children. Environ Res.

$504 \quad 2021 ; 195: 110870$. doi:10.1016/j.envres.2021.110870

27. Kannan S, Dvonch JT, Schulz AJ, et al. Exposure to fine particulate matter and acute effects

506 on blood pressure: effect modification by measures of obesity and location. J Epidemiol

507 Community Health. 2010;64(1):68-74. doi:10.1136/jech.2008.081836

508 28. Dvonch JT, Kannan S, Schulz AJ, et al. Acute effects of ambient particulate matter on blood 509 pressure: differential effects across urban communities. Hypertension. 2009;53:853-859.

510 29. Zanobetti A, Canner MJ, Stone PH, et al. Ambient pollution and blood pressure in cardiac

511 rehabilitation patients. Circulation. 2004;110(15):2184-2189.

512 doi:10.1161/01.CIR.0000143831.33243.D8

513 30. Cakmak S, Dales R, Leech J, Liu L. The influence of air pollution on cardiovascular and

514 pulmonary function and exercise capacity: Canadian Health Measures Survey (CHMS).

515 Environ Res. 2011;111(8):1309-1312. doi:10.1016/j.envres.2011.09.016

516 31. Péter S, Holguin F, Wood LG, et al. Nutritional Solutions to Reduce Risks of Negative Health

517 Impacts of Air Pollution. Nutrients. 2015;7(12):10398-10416. Published 2015 Dec 10.

518 doi:10.3390/nu7125539

519 32. Rich DQ, Zareba W, Beckett W, et al. Are ambient ultrafine, accumulation mode, and fine

520 particles associated with adverse cardiac responses in patients undergoing cardiac

521 rehabilitation? [published correction appears in Environ Health Perspect. 2012

522 Sep;120(9):A345]. Environ Health Perspect. 2012;120(8):1162-1169.

523 doi:10.1289/ehp.1104262

524 33. Kim E, Hopke PK, Pinto JP, Wilson WE. Spatial variability of fine particle mass,

525 components, and source contributions during the regional air pollution study in St. Louis.

526 Environ Sci Technol. 2005;39(11):4172-4179. doi:10.1021/es049824x 
527 34. Kim SB, Temiyasathit C, Chen VC, Park SK, Sattler M, Russell AG. Characterization of 528 spatially homogeneous regions based on temporal patterns of fine particulate matter in the 529 continental United States. J Air Waste Manag Assoc. 2008;58(7):965-975.

$530 \quad$ doi:10.3155/1047-3289.58.7.965 
Table 1. Demographic and physiologic characteristics of 136,008 participants in the WHI Observational Study (OS) and Clinical Trial (CT) components and air pollution exposure metrics throughout follow-up (1993-2005).

\begin{tabular}{|c|c|c|}
\hline & OS & CT \\
\hline Participants, $\mathrm{N}$ & 69,490 & 66,518 \\
\hline Observations, $\mathrm{n}$ & 119,147 & 407,563 \\
\hline Age at visit, years, Mean \pm SD & $64.24 \pm 7.49$ & $66.09 \pm 7.31$ \\
\hline \multicolumn{3}{|l|}{ Region, \% } \\
\hline Northeast & 21.85 & 23.23 \\
\hline South & 26.07 & 24.32 \\
\hline Midwest & 21.15 & 22.51 \\
\hline West & 30.92 & 29.95 \\
\hline \multicolumn{3}{|l|}{ Race/Ethnicity, \% } \\
\hline American Indian or Alaskan Native & 0.47 & 0.39 \\
\hline Asian or Pacific Islander & 2.87 & 2.25 \\
\hline Black or African-American & 5.91 & 8.59 \\
\hline Hispanic/Latino & 4.09 & 4.02 \\
\hline White (not of Hispanic origin) & 85.6 & 83.71 \\
\hline Other & 1.07 & 1.05 \\
\hline Neighborhood-level SEP, Mean \pm SD & $0.35 \pm 5.33$ & $0.26 \pm 5.28$ \\
\hline Tertile 1 & 31.52 & 32.31 \\
\hline Tertile 2 & 32.81 & 33.52 \\
\hline Tertile 3 & 35.67 & 34.17 \\
\hline \multicolumn{3}{|l|}{$\begin{array}{l}\text { Body mass index (BMI), } \mathrm{kg} / \mathrm{m}^{2} \text {, Mean } \pm \\
\mathrm{SD}, \%\end{array}$} \\
\hline At baseline & $26.53 \pm 5.49$ & $28.19 \pm 5.59$ \\
\hline $\mathrm{BMI}<25$ & 46.61 & 31.74 \\
\hline $\mathrm{BMI}>=25$ and $<30$ & 33.18 & 36.64 \\
\hline $\mathrm{BMI}>=30$ & 20.21 & 31.62 \\
\hline Across all visits & $26.53 \pm 5.44$ & $28.60 \pm 5.84$ \\
\hline $\mathrm{BMI}<25$ & 46.19 & 29.9 \\
\hline $\mathrm{BMI}>=25$ and $<30$ & 33.47 & 35.71 \\
\hline $\mathrm{BMI}>=30$ & 20.34 & 34.4 \\
\hline Dietary sodium intake $(\mathrm{mg})$, Mean \pm SD, \% & $2546.92 \pm 1183.68$ & $2688.62 \pm 1160.83$ \\
\hline Tertile 1 & $1510.84 \pm 388.86,36.55$ & $1552.67 \pm 362.79,30.55$ \\
\hline Tertile 2 & $2461.08 \pm 245.75,32.89$ & $2470.48 \pm 246.37,33.71$ \\
\hline Tertile 3 & $3866.13 \pm 1149.87,30.56$ & $3883.00 \pm 1024.69,35.74$ \\
\hline $\begin{array}{l}\text { Combined fruit and vegetable } \\
\text { consumption, medium servings per day, } \%\end{array}$ & $4.34 \pm 2.26$ & $4.12 \pm 2.17$ \\
\hline Tertile 1 & $2.00 \pm 0.66,31.58$ & $2.01 \pm 0.64,34.85$ \\
\hline Tertile 2 & $3.90 \pm 0.56,33.08$ & $3.88 \pm 0.56,33.57$ \\
\hline Tertile 3 & $6.76 \pm 1.66,35.34$ & $6.71 \pm 1.59,31.58$ \\
\hline
\end{tabular}


Pack-years of smoking

Diabetes present , \%

Yes

No

Systolic blood pressure (SBP), $\mathrm{mm} \mathrm{Hg}$

Across all visits

Baseline visit

Diastolic blood pressure (DBP), $\mathrm{mm} \mathrm{Hg}$

Across all visits

Baseline visit

Air pollutants, lag days $0-6$, Mean \pm SD

$\mathrm{PM}_{2.5}\left(\mu \mathrm{g} / \mathrm{m}^{3}\right)$

$\mathrm{PM}_{2.5-10}\left(\mu \mathrm{g} / \mathrm{m}^{3}\right)$

$\mathrm{PM}_{10}\left(\mu \mathrm{g} / \mathrm{m}^{3}\right)$

$\mathrm{NO}_{2}$ (ppb)

Air pollutants, lag days $0-2$, Mean \pm SD

$\mathrm{PM}_{2.5}\left(\mu \mathrm{g} / \mathrm{m}^{3}\right)$

$\mathrm{PM}_{2.5-10}\left(\mu \mathrm{g} / \mathrm{m}^{3}\right)$

$\mathrm{PM}_{10}\left(\mu \mathrm{g} / \mathrm{m}^{3}\right)$

$\mathrm{NO}_{2}$ (ppb)

Air pollutants, lag days $3-5$, Mean \pm SD

$\mathrm{PM}_{2.5}\left(\mu \mathrm{g} / \mathrm{m}^{3}\right) \mathrm{IQR}=7.66$

$\mathrm{PM}_{2.5}$ in IQR units

$\mathrm{PM}_{2.5-10}\left(\mu \mathrm{g} / \mathrm{m}^{3}\right) \mathrm{IQR}=8.46$

$\mathrm{PM}_{2.5-10}$ in IQR units

$\mathrm{PM}_{10}\left(\mu \mathrm{g} / \mathrm{m}^{3}\right) \mathrm{IQR}=12.14$

$\mathrm{PM}_{10}$ in IQR units

$\mathrm{NO}_{2}$ (ppb) IQR=9.88

$\mathrm{NO}_{2}$ in IQR units

Long-term $\mathrm{PM}_{2.5}, \mu \mathrm{g} / \mathrm{m}^{3}$, Mean $\pm \mathrm{SD}, \%$

Tertile 1

Tertile 2

Tertile 3
$9.38 \pm 17.78$

3.73

96.27

$123.45 \pm 16.72$

$126.96 \pm 17.96$

$73.33 \pm 9.00$

$74.73 \pm 9.33$

$13.92 \pm 5.69$

$14.14 \pm 7.12$

$27.99 \pm 8.65$

$19.04 \pm 7.36$

$13.87 \pm 6.70$

$14.49 \pm 8.35$

$28.27 \pm 10.33$

$19.28 \pm 8.12$

$13.88 \pm 6.75$

$1.81 \pm 0.88$

$13.51 \pm 8.18$

$1.60 \pm 0.97$

$27.38 \pm 10.06$

$2.26 \pm 0.83$

$18.45 \pm 7.82$

$1.87 \pm 0.79$

$13.02 \pm 3.74$

$9.49 \pm 1.62,37.92$

$13.32 \pm 0.89,35.63$

$17.67 \pm 2.93,26.45$
7.19

92.81

$125.61 \pm 16.91$

$127.97 \pm 17.40$

$72.72 \pm 9.30$

$75.88 \pm 9.12$

$13.45 \pm 5.64$

$13.39 \pm 6.61$

$27.07 \pm 8.04$

$17.84 \pm 7.03$

$13.39 \pm 6.63$

$13.67 \pm 7.85$

$27.28 \pm 9.83$

$18.01 \pm 7.74$

$13.45 \pm 6.75$

$1.76 \pm 0.88$

$12.82 \pm 7.60$

$1.52 \pm 0.90$

$26.55 \pm 9.62$

$2.19 \pm 0.79$

$17.41 \pm 7.60$

$1.76 \pm 0.77$

$13.84 \pm 4.23$

$9.50 \pm 1.63,32.43$

$13.38 \pm 0.91,32.02$

$18.22 \pm 3.24,35.55$ 
Table 2. Main effects of an IQR change in lag 3-5 day air pollutant exposure metrics on systolic and diastolic blood pressure in the WHI Observational Study (OS) and Clinical Trials (CT) components for $\mathrm{PM}_{2.5}, \mathrm{PM}_{2.5-10}, \mathrm{PM}_{10}$, and $\mathrm{NO}_{2}$.

\begin{tabular}{|c|c|c|c|c|c|c|c|c|c|c|}
\hline \multirow{2}{*}{$\begin{array}{l}\text { Health } \\
\text { Outcome }\end{array}$} & \multirow[t]{2}{*}{ Models } & \multirow[t]{2}{*}{ Air pollutants } & \multicolumn{4}{|c|}{ OS } & \multicolumn{4}{|c|}{ CT } \\
\hline & & & $\mathbf{N}$ & $\beta$ & SE & $p$-value & $\mathbf{N}$ & $\beta$ & SE & $p$-value \\
\hline \multirow[t]{16}{*}{ SBP } & Unadjusted & $\mathrm{PM}_{2.5}$ & 39,537 & 0.02 & 0.093 & 0.846 & 259,571 & -0.01 & 0.031 & 0.843 \\
\hline & & $\mathrm{PM}_{2.5-10}$ & 39,537 & -0.12 & 0.085 & 0.151 & 259,571 & -0.08 & 0.031 & 0.008 \\
\hline & & $\mathbf{P M}_{10}$ & 105,214 & -0.20 & 0.054 & 0.0003 & 385,740 & -0.09 & 0.027 & 0.001 \\
\hline & & $\mathrm{NO}_{2}$ & 105,214 & 0.12 & 0.062 & 0.046 & 385,740 & 0.17 & 0.034 & $<0.0001$ \\
\hline & Basic & $\mathrm{PM}_{2.5}$ & 39,425 & 0.09 & 0.091 & 0.320 & 259,035 & 0.06 & 0.032 & 0.062 \\
\hline & & $\mathrm{PM}_{2.5-10}$ & 39,425 & -0.04 & 0.088 & 0.680 & 259,035 & 0.01 & 0.032 & 0.685 \\
\hline & & $\mathrm{PM}_{10}$ & 104,916 & -0.05 & 0.055 & 0.379 & 384,953 & 0.03 & 0.027 & 0.271 \\
\hline & & $\mathrm{NO}_{2}$ & 104,916 & 0.01 & 0.066 & 0.859 & 384,953 & 0.37 & 0.037 & $<0.0001$ \\
\hline & Fully adjusted & $\mathrm{PM}_{2.5}$ & 37,646 & 0.18 & 0.092 & 0.045 & 248,334 & 0.07 & 0.032 & 0.026 \\
\hline & & $\mathrm{PM}_{2.5-10}$ & 37,646 & -0.12 & 0.089 & 0.178 & 248,334 & 0.01 & 0.033 & 0.719 \\
\hline & & $\mathrm{PM}_{10}$ & 100,041 & -0.07 & 0.056 & 0.205 & 369,230 & 0.04 & 0.028 & 0.117 \\
\hline & & $\mathrm{NO}_{2}$ & 100,041 & 0.16 & 0.067 & 0.020 & 369,230 & 0.45 & 0.037 & $<0.0001$ \\
\hline & $\begin{array}{l}\text { Fully adjusted + } \\
\text { calendar time }\end{array}$ & $\mathrm{PM}_{2.5}$ & 37,646 & 0.13 & 0.092 & 0.175 & 248,334 & -0.06 & 0.032 & 0.067 \\
\hline & & $\mathrm{PM}_{2.5-10}$ & 37,646 & -0.06 & 0.089 & 0.514 & 248,334 & -0.04 & 0.033 & 0.284 \\
\hline & & $\mathrm{PM}_{10}$ & 100,041 & -0.07 & 0.056 & 0.202 & 369,230 & -0.05 & 0.028 & 0.064 \\
\hline & & $\mathrm{NO}_{2}$ & 100,041 & -0.13 & 0.067 & 0.061 & 369,230 & -0.02 & 0.038 & 0.608 \\
\hline \multirow[t]{8}{*}{ DBP } & Unadjusted & $\mathrm{PM}_{2.5}$ & 39,537 & 0.22 & 0.051 & $<0.0001$ & 259,571 & 0.15 & 0.018 & $<0.0001$ \\
\hline & & $\mathrm{PM}_{2.5-10}$ & 39,537 & -0.13 & 0.047 & 0.004 & 259,571 & 0.04 & 0.018 & 0.032 \\
\hline & & $\mathrm{PM}_{10}$ & 105,214 & -0.02 & 0.030 & 0.444 & 385,740 & 0.12 & 0.016 & $<0.0001$ \\
\hline & & $\mathrm{NO}_{2}$ & 105,214 & 0.45 & 0.034 & $<0.0001$ & 385,740 & 0.77 & 0.020 & $<0.0001$ \\
\hline & Basic & $\mathrm{PM}_{2.5}$ & 39,425 & 0.14 & 0.052 & 0.006 & 259,035 & 0.06 & 0.018 & 0.001 \\
\hline & & $\mathrm{PM}_{2.5-10}$ & 39,425 & 0.01 & 0.050 & 0.894 & 259,035 & 0.07 & 0.019 & 0.000 \\
\hline & & $\mathbf{P M}_{10}$ & 104,916 & 0.00 & 0.032 & 0.878 & 384,953 & 0.06 & 0.016 & 0.000 \\
\hline & & & & & & & & & & 26 \\
\hline
\end{tabular}




\begin{tabular}{llrllllllc} 
& $\mathbf{N O}_{2}$ & 104,916 & $\mathbf{0 . 3 6}$ & $\mathbf{0 . 0 3 8}$ & $<\mathbf{0 . 0 0 0 1}$ & 384,953 & $\mathbf{0 . 3 5}$ & $\mathbf{0 . 0 2 1}$ & $<\mathbf{0 . 0 0 0 1}$ \\
Fully adjusted & $\mathbf{P M}_{2.5}$ & 37,646 & $\mathbf{0 . 1 6}$ & $\mathbf{0 . 0 5 2}$ & $\mathbf{0 . 0 0 2}$ & 248,334 & $\mathbf{0 . 0 6}$ & $\mathbf{0 . 0 1 9}$ & $\mathbf{0 . 0 0 1}$ \\
& $\mathbf{P M}_{2.5-10}$ & 37,646 & 0.00 & 0.051 & 1.000 & 248,334 & $\mathbf{0 . 0 8}$ & $\mathbf{0 . 0 1 9}$ & $<0.0001$ \\
& $\mathbf{P M}_{10}$ & 100,041 & 0.01 & 0.039 & 0.898 & 369,230 & $\mathbf{0 . 0 7}$ & $\mathbf{0 . 0 1 6}$ & $<\mathbf{0 . 0 0 0 1}$ \\
& $\mathbf{N O}_{2}$ & 100,041 & $\mathbf{0 . 4 1}$ & $\mathbf{0 . 0 3 8}$ & $<\mathbf{0 . 0 0 0 1}$ & 369,230 & $\mathbf{0 . 3 8}$ & $\mathbf{0 . 0 2 2}$ & $<\mathbf{0 . 0 0 0 1}$ \\
& & & & & & & \\
Fully adjusted + & $\mathbf{P M}_{2.5}$ & 37,646 & 0.09 & 0.052 & 0.086 & 248,334 & -0.02 & 0.019 & 0.362 \\
calendar time & $\mathbf{P M}_{2.5-10}$ & 37,646 & 0.07 & 0.051 & 0.146 & 248,334 & $\mathbf{0 . 0 5}$ & $\mathbf{0 . 0 1 9}$ & $\mathbf{0 . 0 1 3}$ \\
& $\mathbf{P M}_{10}$ & 100,041 & 0.01 & 0.032 & 0.837 & 369,230 & 0.02 & 0.016 & 0.268 \\
& $\mathbf{N O}_{2}$ & 100,041 & $\mathbf{0 . 3 2}$ & $\mathbf{0 . 0 3 9}$ & $<\mathbf{0 . 0 0 0 1}$ & 369,230 & $\mathbf{0 . 1 3}$ & $\mathbf{0 . 0 2 2}$ & $<\mathbf{0 . 0 0 0 1}$ \\
\hline
\end{tabular}

*: Basic model adjusted for age, race/ethnicity, arm group (for CT), region, day of the week, season and random slope for age; Fully

adjusted model adjusted for age, race/ethnicity, arm group (for CT), region, day of the week, season, BMI, SEP, pack- year of smoking,

diabetes and random slope for age.

**: $\mathrm{PM}$ is particulate matter; $\mathrm{PM}_{2.5}$ is $\mathrm{PM}<2.5 \mu \mathrm{m} ; \mathrm{PM}_{2.5-10}$ is $2.5 \mu \mathrm{m}<\mathrm{PM}<10 \mu \mathrm{m} ; \mathrm{PM}_{10}$ is $\mathrm{PM}<10 \mu \mathrm{m}$; $\mathrm{NO}_{2}$ is nitrogen dioxide. 
Table 3. Effect modification of lag 3-5 day air pollutant exposures assessed using stratification by BMI, SEP, diabetes, and long-term PM 2.5 level based on fully adjusted models not controlling for calendar time (when interaction terms were significant in Table 2). *

\begin{tabular}{|c|c|c|c|c|c|c|c|c|c|c|c|c|c|}
\hline \multirow{2}{*}{$\begin{array}{l}\text { Health } \\
\text { Outcome }\end{array}$} & \multirow{2}{*}{$\begin{array}{l}\text { Air } \\
\text { pollutant }\end{array}$} & \multirow{2}{*}{\multicolumn{2}{|c|}{$\begin{array}{l}\text { Effect modifier } \\
\text { and strata** }\end{array}$}} & \multicolumn{5}{|c|}{ os } & \multicolumn{5}{|c|}{ CT } \\
\hline & & & & $\mathbf{N}$ & $\beta$ & SE & $p$-value & $\begin{array}{c}p \text {-value for } \\
\text { interaction } \\
\text { term }\end{array}$ & $\mathbf{N}$ & $\beta$ & SE & $p$-value & $\begin{array}{c}p \text {-value for } \\
\text { interaction } \\
\text { term }\end{array}$ \\
\hline \multirow[t]{16}{*}{ SBP } & $\mathrm{PM}_{2.5}$ & SEP & Tertile 1 & 12,085 & 0.52 & 0.174 & 0.003 & 0.002 & 81,411 & 0.16 & 0.060 & 0.009 & 0.0002 \\
\hline & & & Tertile 2 & 12,312 & 0.19 & 0.161 & 0.230 & & 83,977 & 0.12 & 0.056 & 0.034 & \\
\hline & & & Tertile 3 & 13,249 & -0.10 & 0.148 & 0.501 & & 82,946 & -0.04 & 0.051 & 0.456 & \\
\hline & & $\mathrm{BMI}$ & Low & & & & & & 69,063 & -0.02 & 0.060 & 0.718 & 0.026 \\
\hline & & & Medium & & & & & & 89,311 & 0.13 & 0.054 & 0.013 & \\
\hline & & & High & & & & & & 89,960 & 0.12 & 0.055 & 0.030 & \\
\hline & & Diabetes & No & & & & & & 227,817 & 0.05 & 0.033 & 0.144 & 0.0029 \\
\hline & & & Yes & & & & & & 20,517 & 0.27 & 0.126 & 0.035 & \\
\hline & $\mathrm{NO}_{2}$ & SEP & Tertile 1 & 31,923 & 0.63 & 0.126 & $<0.0001$ & $<0.0001$ & 120,928 & 0.61 & 0.070 & $<0.0001$ & 0.0006 \\
\hline & & & Tertile 2 & 32,813 & 0.21 & 0.118 & 0.070 & & 124,057 & 0.53 & 0.066 & $<0.0001$ & \\
\hline & & & Tertile 3 & 35,305 & -0.22 & 0.109 & 0.040 & & 124,245 & 0.33 & 0.060 & $<0.0001$ & \\
\hline & & $\mathrm{BMI}$ & Low & & & & & & 106,919 & 0.38 & 0.068 & $<0.0001$ & $<0.0001$ \\
\hline & & & Medium & & & & & & 133,384 & 0.43 & 0.062 & $<0.0001$ & \\
\hline & & & High & & & & & & 128,927 & 0.62 & 0.065 & $<0.0001$ & \\
\hline & & Diabetes & No & & & & & & 343,000 & 0.40 & 0.039 & $<0.0001$ & $<0.0001$ \\
\hline & & & Yes & & & & & & 26,230 & 0.92 & 0.155 & $<0.0001$ & \\
\hline \multirow[t]{8}{*}{ DBP } & $\mathrm{PM}_{2.5}$ & SEP & Tertile 1 & 12,085 & 0.39 & 0.098 & $<0.0001$ & 0.0125 & & & & & \\
\hline & & & Tertile 2 & 12,312 & 0.08 & 0.092 & 0.402 & & & & & & \\
\hline & & & Tertile 3 & 13,249 & 0.07 & 0.084 & 0.416 & & & & & & \\
\hline & & Diabetes & No & & & & & & 227,817 & 0.05 & 0.019 & 0.005 & 0.0049 \\
\hline & & & Yes & & & & & & 20,517 & 0.18 & 0.072 & 0.010 & \\
\hline & & $\begin{array}{l}\text { Long- } \\
\text { term } \\
\mathrm{PM}_{2.5}\end{array}$ & Tertile 1 & & & & & & 63,559 & -0.01 & 0.046 & 0.811 & 0.0133 \\
\hline & & & Tertile 2 & & & & & & 74,311 & 0.09 & 0.038 & 0.024 & \\
\hline & & & Tertile 3 & & & & & & 110,464 & 0.05 & 0.026 & 0.039 & \\
\hline
\end{tabular}


$\begin{array}{lllrrrr}\mathbf{P M}_{10} \quad \text { Diabetes } & \text { No } & 343,000 & 0.06 & 0.017 & 0.001 \\ & & \text { Yes } & 26,230 & 0.20 & 0.067 & 0.003\end{array}$

$\begin{array}{llll}26,230 & 0.20 & 0.067 & 0.003\end{array}$

0.0012

Note: Effect modification for $\mathrm{NO}_{2}-$ DBP association was evaluated in fully-adjusted models + calendar time. These results are presented in Table 5.

*Models adjusted for age, race/ethnicity, arm group (for CT), region, day of the week, season, BMI, SEP, pack-years of smoking, diabetes, and random slope for age.

${ }^{\star *}$ Categorized by tertile of SEP score, BMI, and/or long-term $\mathrm{PM}_{2.5}$ level score separately. 
Table 4. Effect modification of lag 3-5 day air pollutant exposures assessed using stratification by BMI, SEP, diabetes, sodium intake, and fruit and vegetable consumption based on fully-adjusted + calendar time models*.

\begin{tabular}{|c|c|c|c|c|c|c|c|c|c|c|c|c|c|}
\hline \multirow{2}{*}{$\begin{array}{l}\text { Health } \\
\text { Outcome }\end{array}$} & \multirow{2}{*}{$\begin{array}{l}\text { Air } \\
\text { pollutant }\end{array}$} & \multirow{2}{*}{\multicolumn{2}{|c|}{$\begin{array}{l}\text { Effect modifier and } \\
\text { strata** }^{* *}\end{array}$}} & \multicolumn{5}{|c|}{ OS } & \multicolumn{5}{|c|}{ CT } \\
\hline & & & & $\mathbf{N}$ & $\beta$ & SE & $p$-value & $\begin{array}{l}p \text {-value for } \\
\text { interaction } \\
\text { term }\end{array}$ & $\mathbf{N}$ & $\beta$ & SE & $p$-value & $\begin{array}{l}p \text {-value for } \\
\text { interaction } \\
\text { term }\end{array}$ \\
\hline \multirow[t]{13}{*}{ DBP } & \multirow[t]{13}{*}{$\mathrm{NO}_{2}$} & \multirow[t]{3}{*}{ SEP } & Tertile 1 & 31,923 & 0.58 & 0.071 & $<0.0001$ & $<0.0001$ & 120,928 & 0.22 & 0.041 & $<0.0001$ & $<0.0001$ \\
\hline & & & Tertile 2 & 32,813 & 0.30 & 0.068 & $<0.0001$ & & 124,057 & 0.14 & 0.039 & 0.001 & \\
\hline & & & Tertile 3 & 35,305 & 0.18 & 0.063 & 0.004 & & 124,245 & 0.10 & 0.036 & 0.005 & \\
\hline & & \multirow[t]{2}{*}{ BMI } & Low & & & & & & 106,919 & 0.13 & 0.040 & 0.001 & $<0.0001$ \\
\hline & & & Medium & & & & & & 133,384 & 0.13 & 0.036 & 0.000 & \\
\hline & & \multirow[t]{2}{*}{ Diabetes } & No & & & & & & 343,000 & 0.12 & 0.023 & $<0.0001$ & $<0.0001$ \\
\hline & & & Yes & & & & & & 26,230 & 0.38 & 0.090 & $<0.0001$ & \\
\hline & & \multirow{3}{*}{$\begin{array}{l}\text { Sodium } \\
\text { intake }\end{array}$} & Tertile 1 & 34,448 & 0.42 & 0.065 & $<0.0001$ & \multirow[t]{3}{*}{0.0311} & & & & & \\
\hline & & & Tertile 2 & 32,371 & 0.25 & 0.068 & 0.0002 & & & & & & \\
\hline & & & Tertile 3 & 29,469 & 0.33 & 0.072 & $<0.0001$ & & & & & & \\
\hline & & \multirow{3}{*}{$\begin{array}{l}\text { Fruit and } \\
\text { vegetable } \\
\text { consumption }\end{array}$} & Tertile 1 & 29,434 & 0.47 & 0.072 & $<0.0001$ & \multirow[t]{3}{*}{0.0426} & & & & & \\
\hline & & & Tertile 2 & 31,970 & 0.32 & 0.069 & $<0.0001$ & & & & & & \\
\hline & & & Tertile 3 & 34.884 & 0.24 & 0.065 & 0.0002 & & & & & & \\
\hline
\end{tabular}

${ }^{*}$ Fully adjusted + calendar time models included the main effect for each effect modifier (even if not identified as a confounder).

${ }^{* *}$ Categorized by tertile of SEP score, BMI, sodium intake, and fruit and vegetable consumption separately. 
Table 5. Single- and two-pollutant models of lag 3-5 day air pollutant exposures based on fullyadjusted + calendar time models*.

\begin{tabular}{lllcccc}
\hline \multirow{2}{*}{ Model } & \multirow{2}{*}{$\begin{array}{l}\text { Health } \\
\text { Outcome }\end{array}$} & Air pollutant & \multicolumn{4}{c}{ CT } \\
\cline { 4 - 7 } Single-pollutant & DBP & $\mathrm{PM}_{2.5-10}$ & $\mathbf{N}$ & $\boldsymbol{\beta}$ & $\mathbf{S E}$ & $\boldsymbol{p}$-value \\
& & $\mathrm{NO}_{2}$ & 248,334 & $\mathbf{0 . 0 5}$ & $\mathbf{0 . 0 1 9}$ & $\mathbf{0 . 0 1 3}$ \\
& & & 369,230 & $\mathbf{0 . 1 3}$ & $\mathbf{0 . 0 2 2}$ & $<\mathbf{0 . 0 0 0 1}$ \\
& & & & & & \\
Two-pollutant** & $\mathrm{DBP}$ & $\mathrm{PM}_{2.5-10}$ & 248,334 & 0.03 & 0.019 & 0.083 \\
& & $\mathrm{NO}_{2}$ & 248,334 & $\mathbf{0 . 2 0}$ & $\mathbf{0 . 0 2 8}$ & $<\mathbf{0 . 0 0 0 1}$ \\
\hline
\end{tabular}

*: Models adjusted for age, race/ethnicity, arm group (for CT), region, day of the week, season, BMI, SEP,

pack-years of smoking, diabetes, random slope for age and calendar time.

**: The two-pollutant model includes $\mathrm{PM}_{2.5-10}$ and $\mathrm{NO}_{2}$ in the same model. 


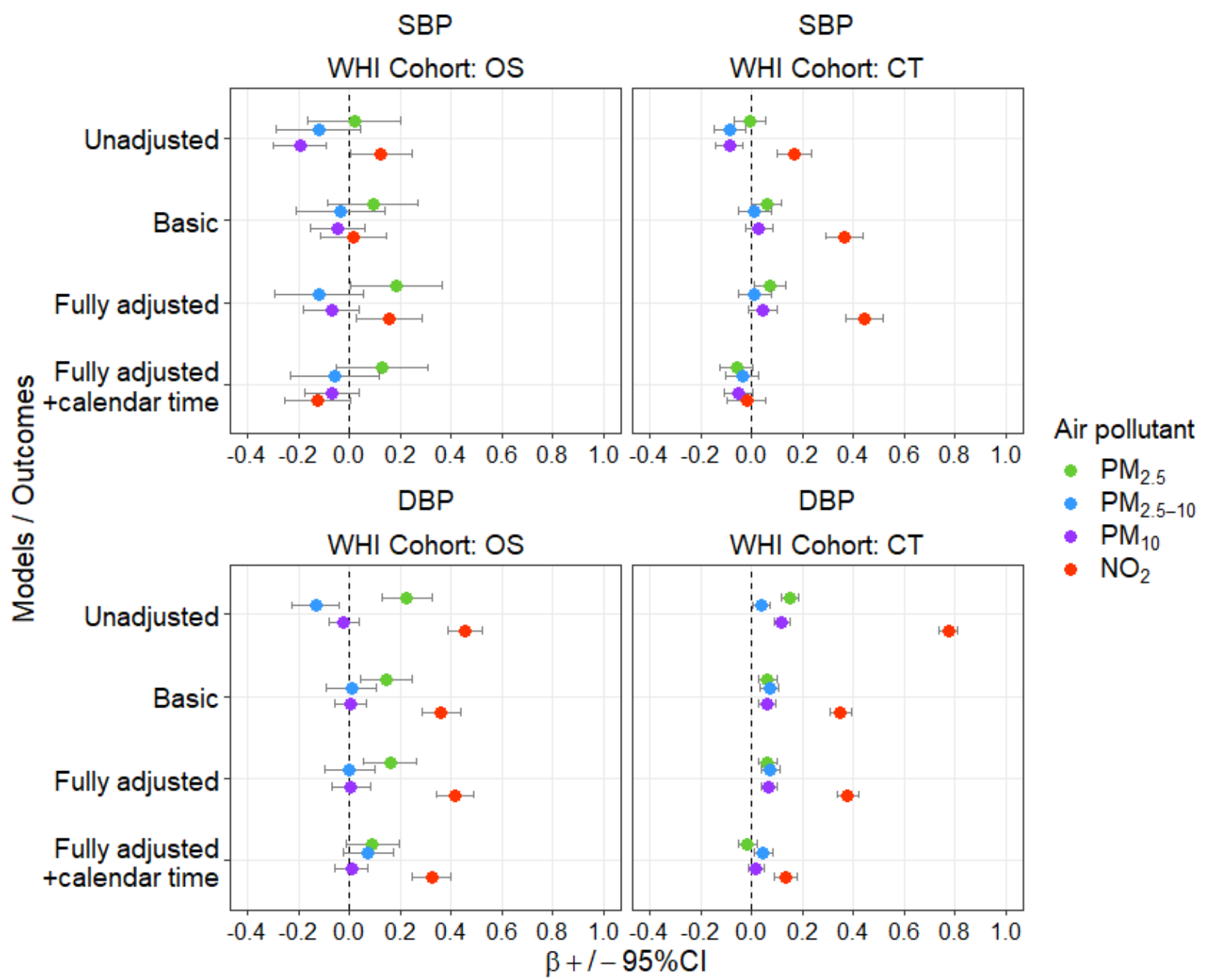

Figure 1. Main effects of an IQR change in exposure metrics averaged over lag days 3-5 on systolic blood pressure (SBP) and diastolic blood pressure (DBP) in the WHI Observational Study (OS) and Clinical Trial (CT) components for unadjusted, basic, fully adjusted, and fully adjusted + calendar time models using data from Table 2. Note: $\mathrm{Cl}$ is confidence interval. 


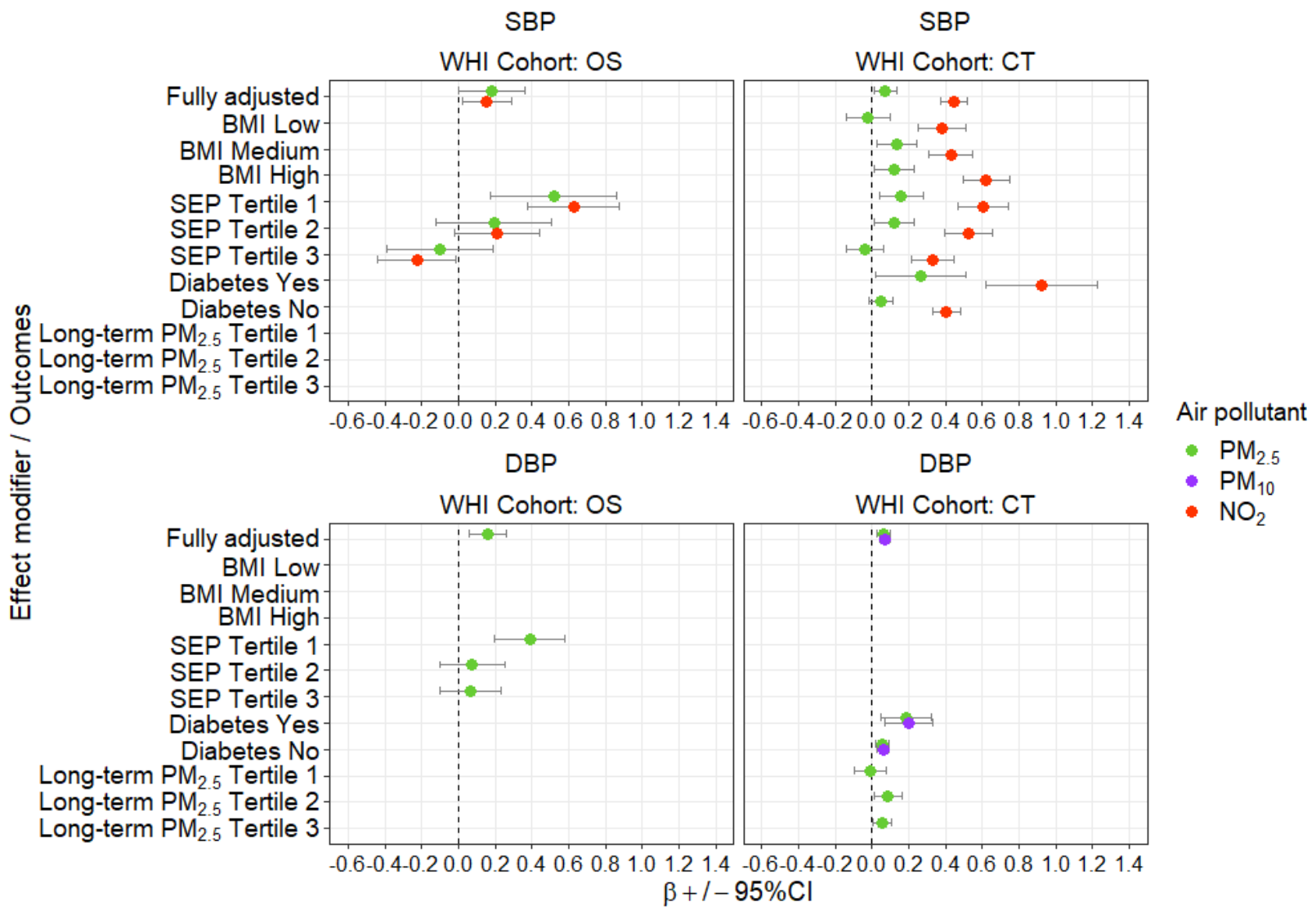

Figure 2. Fully adjusted and stratified effects of an IQR change in exposure metrics averaged over lag days 3-5 on systolic blood pressure (SBP) and diastolic blood pressure (DBP) in models not controlling for calendar time across WHI Observational Study (OS) and Clinical Trials (CT) groups showing effect modification by body mass index (BMI), socioeconomic position (SEP), diabetes, and long-term $\mathrm{PM}_{2.5}$ level based on results in Table 3. Note: $\mathrm{Cl}$ is confidence interval. 


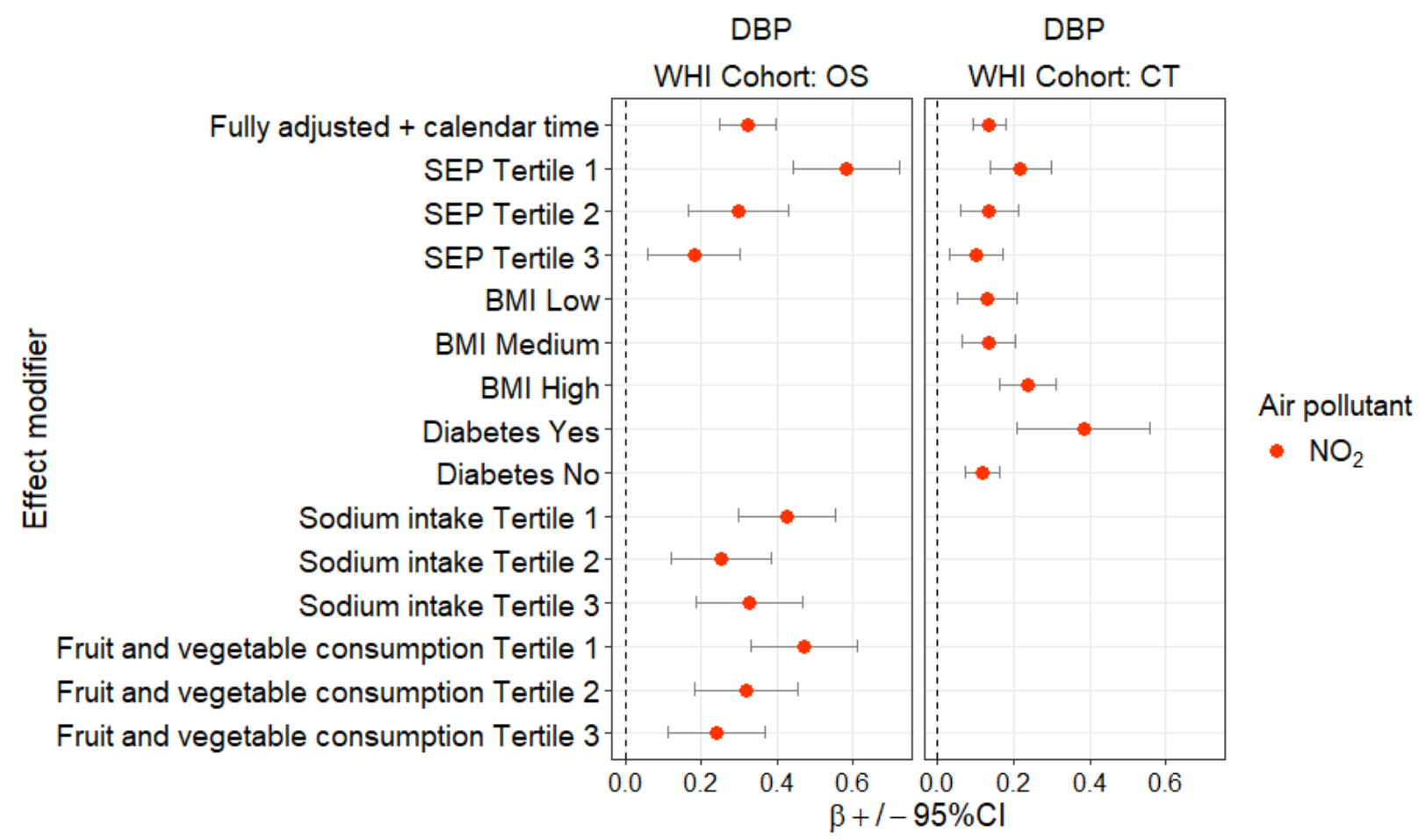

Figure 3. Fully adjusted + calendar time and stratified effects of an IQR change in exposure metrics averaged over lag days 3-5 on diastolic blood pressure (DBP) in the WHI Observational Study (OS) and Clinical Trials (CT) components showing effect modification by BMI, (socioeconomic position) SEP, diabetes, sodium intake, and fruit and vegetable consumption based on results in Table 5. Note: $\mathrm{Cl}$ is confidence interval. 


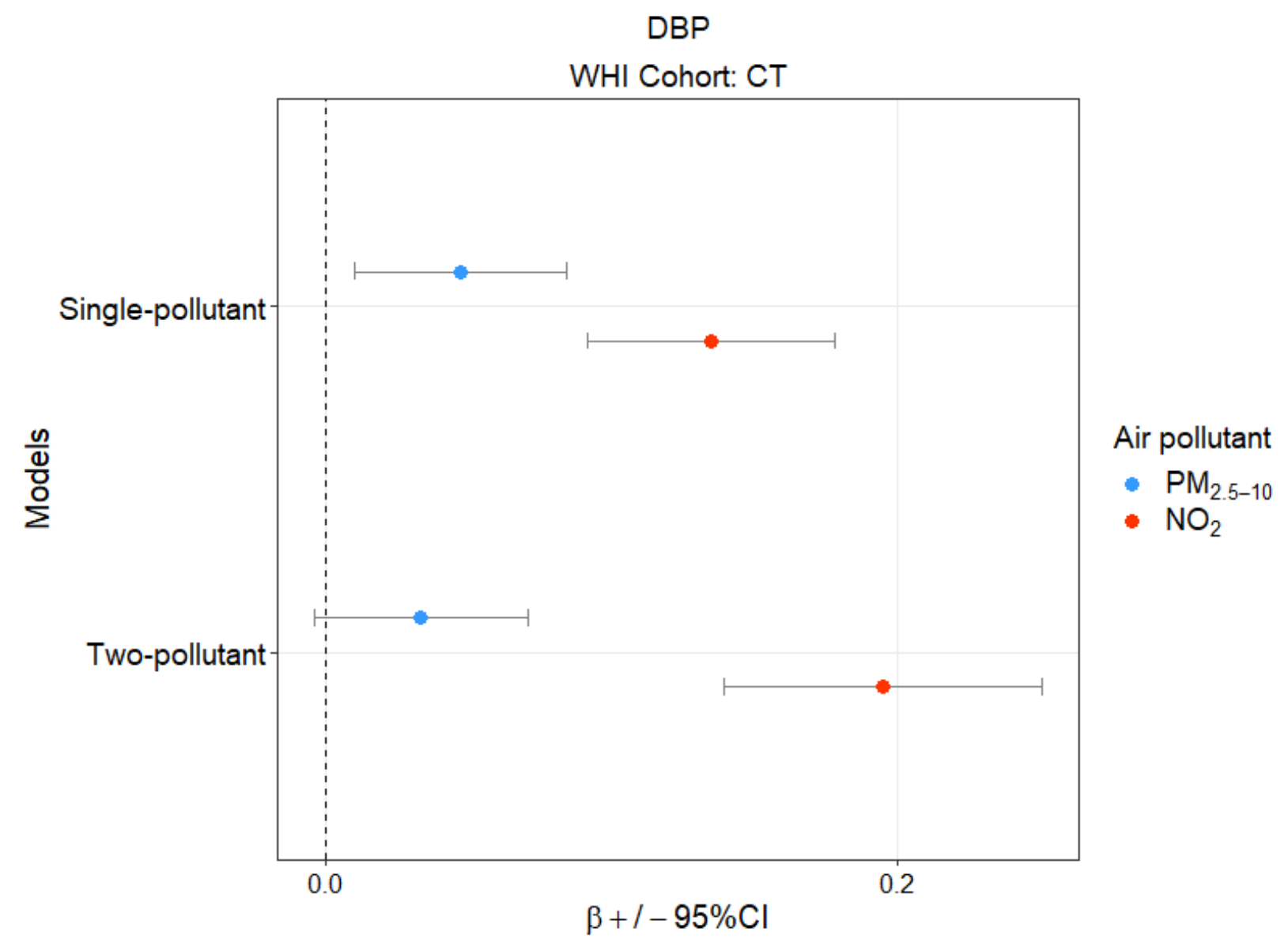

Figure 4. Fully adjusted + calendar time effects of an IQR change in exposure metrics averaged over lag days 3-5 on diastolic blood pressure (DBP) in the WHI Clinical Trial (CT) group from single-pollutant and two-pollutant models. Note: $\mathrm{Cl}$ is confidence interval. 


\section{Supplementary Files}

This is a list of supplementary files associated with this preprint. Click to download.

- SupplementalfilesforWHIBPEH20210930.pdf 